\title{
The Epidemiology of Cognitive Impairment in the Aging Population: Implications for Hearing Loss
}

\author{
Andrea Peracino Sergio Pecorelli \\ Fondazione Giovanni Lorenzini, Milan, Italy; Giovanni Lorenzini Medical Foundation, Houston, Tex., USA
}

\section{Key Words}

Dementia $\cdot$ Cognitive impairment $\cdot$ Aging $\cdot$ Hearing loss .

Sensorial impairments · 'Inflamm-aging' · Alzheimer's

disease

\begin{abstract}
Cognitive impairment and dementia are characterized by a progressive and devastating reduction in most cognitive abilities, functional independence, and social relationships. Dementia represents a substantial financial burden on society, one that is comparable to the financial burden of heart disease and cancer. Due to its insidious onset, cognitive impairment can be clinically silent for several years; therefore, diagnosis occurs late in the disease process, and treatment becomes almost useless. The identification of predictors of dementia may help identify the pathophysiological mechanisms underlying the disease and lead to the development of a more effective medical diagnosis and therapy, and thus an early treatment. Review of the literature suggests that in those individuals with less cognitive impairment (normal/ predementia group), hearing loss has an association with language comprehension, and when cognitive impairment increases (moderate or severe dementia group), the contributing effect of hearing loss as a cognitive ability-impairing factor also increases. Greater understanding of the links be-
\end{abstract}

tween hearing impairment and cognition may have important implications for the screening and diagnosis of cognitive decline in older people with hearing impairment.

(C) 2016 The Author(s)

Published by S. Karger AG, Basel

\section{Introduction}

The progressive reduction in most cognitive abilities, leading to increased dependency and social isolation are devastating consequences of cognitive impairment and dementia in the elderly. Dementia is differentiated according to the etiology of either vascular dementia or neurodegenerative dementia, such as Alzheimer's disease, Lewy body disease, and frontotemporal disease [Prince et al., 2013; Bang et al., 2015; Walker et al., 2015]. Dementia is characterized by a devastating reduction in cognitive abilities including control of behavior, learning, memory, attention/sleep, language, intelligence, perception and visceral/sexual activities as well as functional independence and social relationships, and represents the most frequent brain disorder.

Over the last 10 years, medical research has addressed the association of cognitive impairment with hearing loss; however, there are many still unanswered epidemiologi-

\section{KARGER \\ E-Mail karger@karger.com www.karger.com/aud}

\section{() 2016 The Author(s) \\ Published by S. Karger AG, Basel 1420-3030/16/0217-0003\$39.50/0}

This article is licensed under the Creative Commons AttributionNonCommercial-NoDerivatives 4.0 International License (CC BYNC-ND) (http://www.karger.com/Services/OpenAccessLicense). Usage and distribution for commercial purposes as well as any distribution of modified material requires written permission.
Andrea Peracino

Fondazione Giovanni Lorenzini

Viale Piave, 35

IT-20129 Milan (Italy)

E-Mail andrea.peracino@lorenzinifoundation.org 
cal and clinical questions [Peracino, 2014]. Frank Lin and colleagues [Lin et al., 2013, 2014] published a number of papers showing that hearing impairment in older adults is independently associated with dementia in cross-sectional studies and with accelerated cognitive decline and incident dementia in longitudinal studies. The association of hearing loss with cognitive impairment underlies the importance of understanding those factors that contribute to the decrease in cognitive functions and may have important implications for screening and diagnosis of cognitive decline in hearing-impaired elderly [Imtiaz et al., 2014].

\section{Prevalence and Costs}

Dementia represents a substantial financial burden on society, one that is similar to the financial burden of heart disease and cancer. In the aging population, understanding cognitive functions represent a fundamental target that is receiving the attention of health systems worldwide. The percentage of the world's population of people over 60 years of age is expected to increase. The numbers of people with dementia in high-, middle-, and low-income countries between 2010 and 2050 is expected to increase from 35 million to 115 million [Alzheimer's Disease International, 2010]. In 2009, the prevalence of dementia among the population aged 60 years and older ranged from $6.5 \%$ in France (and $6.4 \%$ in Italy) to $3.4 \%$ in India with an average of 5.5\% for members of the Convention on the Organisation for Economic Co-operation and Development (OECD) [Wimo et al., 2010]. In 2010, the estimated prevalence of dementia among individuals older than 70 years of age in the USA was 14.7\% [Hurd et al., 2013]. Every year, between 6 and 9 million people suffer from dementia in Europe, the majority being older women.

The yearly monetary cost per person in the USA attributable to dementia, published in 2013, was either USD 56,290 (USD 42,746-69,834) or USD 41,689 (USD $31,017-52,362$ ), dependent upon the method used to value informal care [Hurd et al., 2013]. These individual costs suggest that the total monetary cost of dementia in 2010 was between USD 157 billion and 215 billion [Hurd et al., 2013]. In Europe, the annual economic burden for direct and indirect costs of all brain diseases exceeds EUR 790 billion in comparison to EUR 200 billion spent for cardiovascular disease and EUR 150 billion spent for cancer [Olesen et al., 2012]. In 2009, the direct cost of dementia as a percentage of the gross domestic product in the population aged 60 years and over ranged from $0.79 \%$ in Italy $(0.77 \%$ in France) to $0.13 \%$ in Turkey, with an OECD average of 0.49 [Wimo et al., 2010].

Untreated hearing loss in Europe is projected to cost EUR 213 billion in 2025. It is estimated that 900 million people throughout the world will be hearing impaired, and it is expected that around 90 million of these people will be from Europe [Shield, 2006; Roth et al., 2011]. The yearly costs of untreated hearing loss in some European countries range from a high of EUR 32,000 in Germany to EUR 22,400 in France, EUR 22,000 in the UK, and EUR 21,300 in Italy, to lows of EUR 16,300 in Spain and EUR 14,000 in Poland (included in those costs are both direct and indirect costs of hearing impairment) [Evaluation of the Social and Economic Costs of Hearing Impairment, 2006]. The total operating room time for unilateral and bilateral simultaneous cochlear implantation is 3 and $4 \mathrm{~h}$ $37 \mathrm{~min}$, respectively, with a mean difference of $1 \mathrm{~h}$ and 36 min. The total direct costs for a unilateral cochlear implant (excluding implantable device and surgeon fees) in 2014 were USD 4,362, compared to USD 5,823 for a bilateral cochlear implant. Simultaneous bilateral cochlear implantation can lead to a potential saving of USD 2,901 compared to sequential implantation [Merdad et al., 2014].

\section{Open questions:}

It is very difficult to find the real numbers on the prevalence of dementia and hearing loss in different countries: Are local organizations interested in developing or determining the prevalence? Are countries interested in helping families treat their relatives affected by dementia?

\section{Early Predictors of Dementia}

\section{Biomarkers}

Dementia is associated with aging and in most cases develops and is present subclinically several years before the clinical manifestations. As of today, a major research effort has been focused on the diagnosis of dementia, especially neurodegenerative dementia, when the disease is still clinically silent. In fact, the identification of predictors of dementia may lead to early treatment and may help identify the pathophysiological mechanisms underlying the disease. Several early markers of the disease, such as biological markers in blood and cerebrospinal fluid and neuroimaging, have been studied, findings which could aid in the early diagnosis of Alzheimer's disease [Blennow et al., 1995; Dubois et al., 2007; Uberti et al., 2008; Zwan et al., 2014]. 
During the past few years, several biomarkers have been studied to identify dementia in its early phase. Examples are the measurement of $\beta$-amyloid and tau protein in cerebrospinal fluid [Andreasen et al., 2003; Prvulovic and Hampel, 2011], precursor of $\beta$-amyloid in platelets [Vignini et al., 2013] and plasma lipid profile [Pani et al., 2009; Mapstone et al., 2014], and circulating unfolded p53 [Uberti et al., 2008].

Several biomarkers also for early Alzheimer's disease detection such as cerebrospinal fluid tau protein and $\beta$-amyloid levels have been proposed [Blennow and Hampel, 2003]; moreover, promising biomarkers are detectable in peripheral blood and/or saliva samples [Uberti et al., 2006, 2008; Lanni et al., 2007]. In particular, unfolded p53 protein in blood has been found to be a predictive biomarker for progression from mild cognitive impairment to fully developed Alzheimer's disease [Lanni et al., 2010]. Additionally, a redox profile alteration has been measured with a newly validated method in saliva samples [Prandelli et al., 2013].

Open question:

The prediction of dementia and the clinical steps leading to dementia represent a key unresolved topic: What must be done to develop a rigorous approach to prediction and, possibly, to prevention of cognitive impairment?

\section{Sensorial Impairments}

Amongst predictors of dementia, impairments in hearing, vision, olfaction, and taste have been identified [Behrman et al., 2014]. In particular, it has been shown that people with dementia have difficulties with recognition and identification of odors, suggesting a link to impairment of higher cognitive function. Olfactory impairment is seen in many neurodegenerative conditions but the recognition and identification of odors has not been clearly identified as a link to impairment of higher cognitive function, and there is a lack of uniformity in the results from several studies. However, olfactory impairment has been shown in some studies to be predictive of conversion from mild cognitive impairment to Alzheimer's disease with $85.2 \%$ sensitivity [Wilson et al., 2009].

Results suggest that, in the group with less cognitive impairment (normal/predementia group), hearing loss has a moderate association with language comprehension; however, when cognitive impairment increases (moderate/moderately severe dementia group), the contributing effect of hearing loss as a cognitive ability-impairing factor becomes greater. Deficient cognitive ability, rather than simply auditory problems, explains the language impairment in the elderly.

Epidemiology and Cognitive Impairment
Hearing impairment has been shown to precede cognitive decline in observational studies, as well; however, it is not clear if the hearing loss is an early marker of dementia or a modifiable risk factor [Lin et al., 2011, 2013]. The specific mechanisms underlying the development of dementia may be related to the effects of hearing loss on cortical processing, decreasing cognitive load, and social isolation (due to the loss of auditory stimuli to the cortex) and to pathways that could precipitate other cascading effects of hearing loss on the health of older people. Since both cognitive impairment and hearing loss are age-related diseases, possible common mechanisms may underlie these conditions, such as 'inflamm-aging' or the low-grade chronic inflammatory status that is characteristic of the aging process [Cevenini et al., 2013].

The possible relationship between audiometric hearing thresholds and cognitive performance on language tests was analyzed in a cross-sectional cohort of older adults aged $\geq 65$ years $(n=98)$ with different degrees of cognitive impairment. In the predementia group, reduced hearing levels partially explained language comprehension performance but were not associated with language production. In the dementia group, hearing loss could not be considered as an explanatory factor of poor receptive and production-based language performance. These results are suggestive of cognitive rather than simply auditory problems in explaining the language impairment in the elderly [Lodeiro-Fernández et al., 2015].

Hearing loss is associated with accelerated cognitive decline in older adults. Results underline the importance of addressing the problem of underdiagnosis and undertreatment of hearing loss in elderly adults. The prevention of cognitive aging is expected to be an international research priority, along with cognitive training and physical exercise interventions, which have been shown to have a modest but positive effect on cognitive aging. Auditory rehabilitation programs should be considered as additional potential options to promote successful aging. Hearing rehabilitative treatment is complex and does not simply consist of using a hearing aid; therefore, a welldesigned interventional trial is necessary to demonstrate the effect of a comprehensive auditory rehabilitation program on cognitive aging [Amieva, 2015].

Open question:

Hearing loss is associated with accelerated cognitive decline in older adults: What avenues have been or are being developed by the health authorities to address this problem? 


\section{Comorbidities with Hearing Loss}

\section{Vascular Dysregulation}

Up until the late 1960s, senile dementia, as it was then known, was thought to be attributable to cerebral atherosclerosis and arteriosclerosis. Subsequently, it was thought that cerebrovascular disease only caused dementia when there were many large cortical infarcts. Pathological studies from large cohorts showed that subcortical vascular disease, rather than large cortical infarcts, accounted for most cases of vascular dementia. Mild cognitive impairment caused by cerebrovascular disease has been much less comprehensively studied than the syndrome of mild cognitive impairment caused by Alzheimer's disease, which is largely defined clinically on the basis of an amnesic deficit in the absence of dementia, although diagnostic criteria have been proposed [O'Brien and Thomas, 2015].

The presentation of early vascular disease is much more heterogeneous, because subtle cerebrovascular disease is common with aging. For example, in imaging samples of representative groups of patients aged over 65 years, at least $30 \%$ are known to have had silent infarcts detected via brain imaging, and up to $90 \%$ have varying degrees of white matter lesions. Large-scale genetic studies, which have been informative in many other disorders, are in their infancy for vascular dementia and could add to the understanding of the shared risk with Alzheimer's disease [O'Brien and Thomas, 2015].

Vascular dementia is one of the most common causes of dementia after Alzheimer's disease, contributing to around $15 \%$ of cases. However, unlike Alzheimer's disease, there are no licensed treatments for vascular dementia. Progress in the specialty has been difficult because of uncertainties over disease classification and diagnostic criteria, controversy over the exact nature of the relation between cerebrovascular pathology and cognitive impairment, and the paucity of identifiable tractable treatment targets. Although there is an established relationship between vascular and degenerative Alzheimer's pathology, the mechanistic link between the two has not yet been identified [O'Brien and Thomas, 2015].

\section{Other Chronic Diseases}

Diabetes is considered a risk factor for cognitive impairment and, in longer-term cohort studies, midlife hypertension and raised cholesterol are associated with the onset of Alzheimer's disease in later life [Skoog et al., 1996; Ott et al., 1999; Kivipelto et al., 2001].
Diabetes, hypertension, obesity, dyslipidemia, and metabolic syndrome link to potential mechanisms connecting vascular risk factors and cognitive impairment through: (a) a cerebrovascular disease pathway with infarcts within the white matter that lead to vascular cognitive impairment or (b) blood barrier dysfunctions that are associated with Alzheimer's disease [Reitz et al., 2011].

High blood glucose causes tiny blood vessels in the inner ear to break, disrupting sound reception. Mechanisms related to neuropathic or microvascular factors, inflammation, or hyperglycemia cause an association between diabetes and hearing loss. Up to $30 \%$ of adults with diabetes can experience hearing loss.

Hypothyroidism (underactive thyroid) causes hearing loss that may be conductive, sensorineural or mixed in nature, although it is primarily sensorineural. Most losses are flat, bilateral, or symmetrical with no vestibular involvement. Hearing loss may increase with severity of hypothyroidism.

The kidney and blood supply in the inner ear share physiologic, ultrastructural, and antigenic similarities. Chronic kidney disease shows a higher prevalence of hearing loss among older adults. Diabetes is the cause of $44 \%$ of the cases of chronic renal disease [United States Renal Data System, 2007].

Inadequate blood supply and trauma to inner ear blood vessels can also contribute to hearing loss. Hearing loss appeared in almost $80 \%$ of the people who suffered from cardiovascular disease. Strokes, vascular trauma in the brain affecting the nervous system, motor, and thought processes, can decrease hearing on the affected side of the brain. Broad research has shown the negative influence of impaired cardiovascular health on both peripheral and central auditory systems.

In short and longer latency incidence studies, smoking increases the risk for Alzheimer's disease [Ott et al., 1998; Tyas et al., 2003; Juan et al., 2004; Luchsinger et al., 2005; Whitmer et al., 2005]. Another key pathological mechanism common for several age-related diseases is represented by lipid dysregulation; numerous studies reported a link between lipids and Alzheimer's disease [Xiao et al., 2012; Mapstone et al., 2014]. In general, membrane lipids provide a milieu for transmembrane proteins and can modulate their function. The plasma lipid profile reflects cell membrane integrity.

Open questions:

Diabetes, hypertension, obesity, dyslipidemia, and metabolic syndrome link to potential mechanisms connecting vascular risk factors and cognitive impairment: What are the links between such pathologies and the mechanisms of hearing loss that influ- 
ence the development of cognitive dysfunction over time? How can studies on the integration of auditory function with olfactory, biomarkers of inflammation, lipid dysregulation, and neuropsychological examination serve to identify, at an early stage, the brain neurodegeneration and monitor its progress and the treatment effects?

\section{The Value of Aging}

As mentioned above, hearing impairment is observed to precede cognitive decline in the elderly. The manifestations of age-related hearing loss in many older adults are subtle, and, hence, hearing loss is often perceived as a part of aging. However, the broader consequences of hearing loss in older adults may be relevant for the global health of the elderly [Helzner et al., 2005]. Indeed, age-related hearing loss has been found to be independently associated with poorer cognitive functioning and incident dementia, such that compared to individuals with normal hearing, those with mild, moderate, and severe hearing loss have a 2-, 3-, and 5-fold increased risk of developing dementia, respectively [Lin et al., 2011].

The specific mechanisms underlying aging and hearing loss are unknown but may be related to the effects of hearing loss on cortical processing, increasing cognitive load, and social isolation (due to the loss of auditory stimuli to the cortex) that could precipitate other cascading effects of hearing loss on the health of older people [Cassel et al., 2016].

Since both neurodegenerative dementia (especially Alzheimer's disease) and hearing loss are age-related diseases, possible common mechanisms may underlie these conditions. One of the shared pathogenesis mechanisms of age-related diseases, as already mentioned, is the socalled 'inflamm-aging', which is the low-grade chronic inflammatory status characteristic of the aging process [Cevenini et al., 2013].

Inflamm-aging is the consequence of global reduction in the elderly of their capability to cope with antigenic, chemical, physical and nutritional stressors, and of the concomitant progressive increase in proinflammatory cytokines [Salvioli et al., 2013].

Another key pathological mechanism common for several age-related diseases is represented by lipid dysregulation; numerous studies reported a link between lipids and Alzheimer's disease. In general, membrane lipids provide a milieu for transmembrane proteins and can modulate their function. The plasma lipid profile reflects the cell membrane integrity and may be sensitive to early neurodegeneration [Prince et al., 2013; Tajima et al., 2013; Mapstone et al., 2014].

Open question:

What can be done by clinicians to better treat hearing loss in order to decrease the further development of neurodegenerative dementia?

\section{Conclusions}

Cognitive impairment and dementia are linked to progressive reduction in cognitive abilities, functional independence, and social relationships. In the last decades, there has been increasing evidence that the association of cognitive impairment with hearing loss supports the need for medical research and clinical answers in this area [Peracino, 2014].

Many questions have received satisfying answers thus far, but an efficient medical and political approach to the prevention of hearing loss linked to dementia is lacking. A number of papers [Lin et al., 2013, 2014] have shown that hearing impairment in older adults is independently associated with dementia, thus stressing the importance of understanding the factors that contribute to the decrease in cognitive function. Recent observations confirm that with hearing aids and cochlear implants it is possible to increase the mental health and the quality of life in adults with postlingual hearing loss [Contrera et al., 2016].

Understanding the possible impact of a timely identification of significant hearing loss and the subsequent access to treatment for the aging, hearing-impaired individual as a preventative therapy against the course of cognitive decline, can help realize the value of implementing the appropriate programs to enable them.

\section{Disclosure Statement}

The authors have no conflicts of interest to declare. 


\section{References}

Alzheimer's Disease International: World Alzheimer Report, 2010. http://www.alz.co.uk/ research/files/WorldAlzheimerReport2010. pdf.

Amieva H: Self-reported hearing loss, hearing aids, and cognitive decline in elderly adults: a 25-year study. Am Geriatr Soc 2015;63:20992104.

Andreasen N, Sjogren M, Blennow K: CSF markers for Alzheimer's disease: total tau, phospho-tau and Abeta42. World J Biol Psychiatry 2003;4:147-155.

Bang J, Spina S, Miller BL: Frontotemporal dementia. Lancet 2015;386:1672-1682.

Behrman S, Chouliaras L, Ebmeier KP: Considering the senses in the diagnosis and management of dementia. Maturitas 2014;77:305310 .

Blennow K, Hampel H: CSF markers for incipient Alzheimer's disease. Lancet Neurol 2003;2: 605-613.

Blennow K, Wallin A, Agren H, Spenger C, Siegfried J, Vanmechelen E: Tau protein in cerebrospinal fluid: a biochemical marker for axonal degeneration in Alzheimer disease? Mol Chem Neuropathol 1995;26:231-245.

Cassel C, Penhoet E, Saunders R: Policy solutions for better hearing. JAMA 2016;315:553-554.

Cevenini E, Monti D, Franceschi C: Inflamm-ageing. Curr Opin Clin Nutr Metab Care 2013; 16:14-20.

Contrera KJ, Betz J, Li L, Blake CR, Sung YK, Choi JS, Lin FR: Quality of life after intervention with a cochlear implant or hearing aid. Laryngoscope 2016, Epub ahead of print.

Dubois B, Feldman HH, Jacova C, Dekosky ST, Barberger-Gateau P, Cummings J, Delacourte A, Galasko D, Gauthier S, Jicha G, Meguro K, O’Brien J, Pasquier F, Robert P, Rossor M, Salloway S, Stern Y, Visser PJ, Scheltens P: Research criteria for the diagnosis of Alzheimer's disease: revising the NINCDS-ADRDA criteria. Lancet Neurol 2007;6:734-746.

Evaluation of the Social and Economic Costs of Hearing Impairment, October 2006. Hear-it AISBL.

Helzner EP, Cauley JA, Pratt SR, Wisniewski SR, Zmuda JM, Talbott EO, de Rekeneire N, Harris TB, Rubin SM, Simonsick EM, Tylavsky FA, Newman AB: Race and sex differences in age-related hearing loss: the Health, Aging and Body Composition Study. J Am Geriatr Soc 2005;53:2119-2127.

Hurd MD, Martorell P, Delavande A, Mullen KJ, Langa KM: Monetary costs of dementia in the United States. N Engl J Med 2013;368:13261334.

Imtiaz B, Tolppanen A-M, Kivipelto M, Soininen $\mathrm{H}$ : Future directions in Alzheimer's disease from risk factors to prevention. Biochem Pharmacol 2014;88:661-670.

Juan D, Zhou DH, Li J, Wang JY, Gao C, Chen M: A 2-year follow-up study of cigarette smoking and risk of dementia. Eur J Neurol 2004;11: 277-282.
Kivipelto M, Helkala EL, Laakso MP, Hänninen $\mathrm{T}$, Hallikainen M, Alhainen K, Soininen $\mathrm{H}$, Tuomilehto J, Nissinen A: Midlife vascular risk factors and Alzheimer disease in later life: longitudinal, population based study. Br Med J 2001;322:1447-1451.

Lanni C, Racchi M, Stanga S, Mazzini G, Ranzenigo A, Polotti R, Memo M, Govoni S, Uberti D: Unfolded p53 in blood as a predictive signature of the transition from mild cognitive impairment to Alzheimer's disease. J Alzheimers Dis 2010;20:97-104.

Lanni C, Uberti D, Racchi M, Govoni S, Memo M: Unfolded p53: a potential biomarker for Alzheimer's disease. J Alzheimers Dis 2007;12: 93-99.

Lin FR, Ferrucci L, An Y, Goh JO, Doshi J, Metter EJ, Davatzikos C, Kraut MA, Resnick SM: Association of hearing impairment with brain volume changes in older adults. Neuroimage 2014;90:84-92.

Lin FR, Metter EJ, O’Brien RJ, Resnick SM, Zonderman AB, Ferrucci L: Hearing loss and incident dementia. Arch Neurol 2011;68:214220.

Lin FR, Yaffe K, Xia J, Xue QL, Harris TB, Purchase-Helzner E, Satterfield S, Ayonayon HN, Ferrucci L, Simonsick EM; Health ABC Study Group: Hearing loss and cognitive decline in older adults. JAMA Intern Med 2013;173: 293-299.

Lodeiro-Fernández L, Lorenzo-López L, Maseda A, Núñez-Naveira L, Rodríguez-Villamil JL, Millán-Calenti JC: The impact of hearing loss on language performance in older adults with different stages of cognitive function. Clin Interv Aging 2015;10:695-702.

Luchsinger JA, Reitz C, Honig LS, Tang MX, Shea S, Mayeux R: Aggregation of vascular risk factors and risk of incident Alzheimer disease. Neurology 2005;65:545-551.

Mapstone M, Cheema AK, Fiandaca MS, Zhong X, Mhyre TR, Macarthur LH, Hall WJ, Fisher SG, Peterson DR, Haley JM, Nazar MD, Rich SA, Berlau DJ, Peltz CB, Tan MT, Kawas CH, Federoff HJ: Plasma phospholipids identify antecedent memory impairment in older adults. Nat Med 2014;20:415-418.

Merdad M, Wolter NE, Cushing SL, Gordon KA, Papsin BC: Surgical efficiency in bilateral cochlear implantation: a cost analysis. Cochlear Implants Int 2014;15:43-47.

O’Brien JT, Thomas A: Vascular dementia. Lancet 2015;386:1698-1706.

Olesen J, Gustavsson A, Svensson M, Wittchen HU, Jonsson B; CDBE2010 study group; European Brain Council: The economic cost of brain disorders in Europe. Eur J Neurol 2012; 19:155-162.

Ott A, Slooter AJ, Hofman A, van Harskamp F, Witteman JC, Van Broeckhoven C, van Duijn CM, Breteler MM: Smoking and risk of dementia and Alzheimer disease in a population-based cohort study: the Rotterdam Study. Lancet 1998;351:1841-1843.
Ott A, Stolk RP, van Harskamp F, Pols HA, Hofman A, Breteler MM: Diabetes mellitus and the risk of dementia: the Rotterdam Study. Neurology 1999;53:1937-1942.

Pani A, Mandas A, Diaz G, Abete C, Cocco PL, Angius F, Brundu A, Mucaka N, Pais ME, Saba A, Barberini L, Zaru C, Palmas M, Putzu PF, Mocali A, Paoletti F, La Colla P, Dessi S: Accumulation of neutral lipids in peripheral blood mononuclear cells as a distinctive trait of Alzheimer patients and asymptomatic subjects at risk of disease. BMC Med 2009;7:66.

Peracino A: Hearing loss and dementia in the aging population. Audiol Neurotol 2014;19 (suppl 1):6-9.

Prandelli C, Parola C, Buizza L, Delbarba A, Marziano M, Salvi V, Zacchi V, Memo M, Sozzani S, Calza S, Uberti D, Bosisio D: Sulphurous thermal water increases the release of the antiinflammatory cytokine IL-10 and modulates antioxidant enzyme activity. Int J Immunopathol Pharmacol 2013;26:633-646.

Prince M, Bryce R, Albanese E, Wimo A, Ribeiro $\mathrm{W}$, Ferri CP: The global prevalence of dementia: a systematic review and meta-analysis. Alzheimers Dement 2013;9:63-75.e2.

Prvulovic D, Hampel H: Amyloid $\beta$ (A $\beta)$ and phospho-tau (p-tau) as diagnostic biomarkers in Alzheimer's disease. Clin Chem Lab Med 2011;49:367-374.

Reitz C, Brayne C, Mayeux R: Epidemiology of Alzheimer disease. Nat Rev Neurol 2011;7: 137-152.

Roth TN, Hanebuth D, Probst R: Prevalence of age-related hearing loss in Europe: a review. Arch Otorhinolaryngol 2011;268:1101-1107.

Salvioli S, Monti D, Lanzarini C, Conte M, Pirazzini C, Bacalini MG, Garagnani P, Giuliani C, Fontanesi E, Ostan R, Bucci L, Sevini F, Yani SL, Barbieri A, Lomartire L, Borelli V, Vianello D, Bellavista E, Martucci M, Cevenini E, Pini E, Scurti M, Biondi F, Santoro A, Capri M, Franceschi C: Immune system, cell senescence, aging and longevity - inflammaging reappraised. Curr Pharm Des 2013;19: 1675-1679.

Shield B: Evaluation of the social and economic costs of hearing impairment. Hear-it, 2006. http://www.hear-it.org.

Skoog I, Lernfelt B, Landahl S, Palmertz B, Andreasson LA, Nilsson L, Persson G, Odén A, Svanborg A: 15-year longitudinal study of blood pressure and dementia. Lancet 1996; 347:1141-1145.

Tajima Y, Ishikawa M, Maekawa K, Murayama M, Senoo Y, Nishimaki-Mogami T, Nakanishi H, Ikeda K, Arita M, Taguchi R, Okuno A, Mikawa R, Niida S, Takikawa O, Saito Y: Lipidomic analysis of brain tissues and plasma in a mouse model expressing mutated human amyloid precursor protein/tau for Alzheimer's disease. Lipids Health Dis 2013;12:68. 
Tyas SL, White LR, Petrovitch H, Webster Ross G, Foley DJ, Heimovitz HK, Launer LJ: Mid-life smoking and late-life dementia: the Honolulu-Asia Aging Study. Neurobiol Aging 2003; 24:589-596.

Uberti D, Lanni C, Carsana T, Francisconi S, Missale C, Racchi M, Govoni S, Memo M: Identification of a mutant-like conformation of p53 in fibroblasts from sporadic Alzheimer's disease patients. Neurobiol Aging 2006;27:11931201.

Uberti D, Lanni C, Racchi M, Govoni S, Memo M: Conformationally altered p53: a putative peripheral marker for Alzheimer's disease. Neurodegener Dis 2008;5:209-211.

United States Renal Data System: USRDS 2007 Annual Data Report. Bethesda, National Institute of Diabetes and Digestive and Kidney
Diseases, National Institutes of Health, US Department of Health and Human Services, 2007.

Vignini A, Morganti S, Salvolini E, Sartini D, Luzzi S, Fiorini R, Provinciali L, Di Primio R, Mazzanti L, Emanuelli M: Amyloid precursor protein expression is enhanced in human platelets from subjects with Alzheimer's disease and frontotemporal lobar degeneration: a real-time PCR study. Exp Gerontol 2013;48: 1505-1508.

Walker Z, Possin KL, Boeve BF, Aarsland D: Lewy body dementias. Lancet 2015;386: 1683-1697.

Whitmer RA, Sidney S, Selby J, Johnston SC, Yaffe K: Midlife cardiovascular risk factors and risk of dementia in late life. Neurology 2005;64:277-281.
Wilson RS, Arnold SE, Schneider JA, Boyle PA, Buchman AS, Bennett DA: Olfactory impairment in presymptomatic Alzheimer's disease. Ann NY Acad Sci 2009;1170:730-735.

Wimo A, Winblad B, Jönsson L: The worldwide societal costs of dementia: Estimates for 2009. Alzheimers Dement 2010;6:98-103.

Xiao Z, Wang J, Chen W, Wang P, Zeng H, Chen $\mathrm{W}$ : Association studies of several cholesterolrelated genes (ABCA1, CETP and LIPC) with serum lipids and risk of Alzheimer's disease. Lipids Health Dis 2012;11:163.

Zwan M, van Harten A, Ossenkoppele R, Bouwman F, Teunissen C, Adriaanse S, Lammertsma A, Scheltens P, van Berckel B, van der Flier W: Concordance between cerebrospinal fluid biomarkers and $\left[{ }^{11} \mathrm{C}\right] \mathrm{PIB}$ PET in a memory clinic cohort. J Alzheimers Dis 2014;41:801-807. 